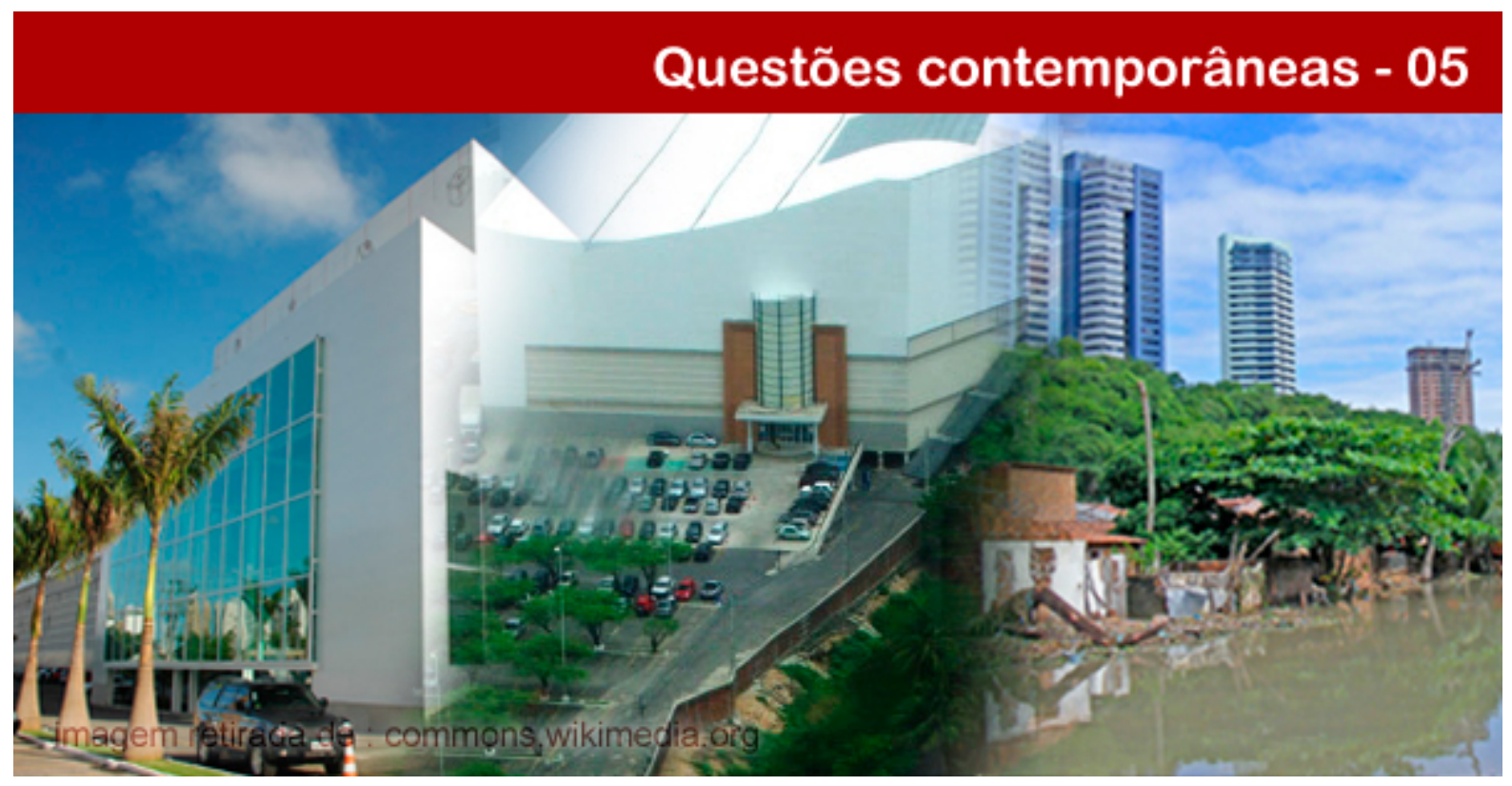

\title{
ESTUDO DE CASO DA EXPANSÃO DO SHOPPING MANAÍRA E COMUNIDADE SÃO JOSÉ SOBRE O RIO JAGUARIBE EM JOÃO PESSOA-PB.
}

\author{
Monalisa Cristina Silva Medeiros \\ Doutoranda em Recursos Naturais pela Universidade Federal de Campina Grande (UFCG). E-mail: \\ monalisacristinasm@hotmail.com.
}

\section{Josué Barreto da Silva Júnior}

Mestre em Recursos Naturais pela Universidade Federal de Campina Grande (UFCG). E-mail: josuebarretojunior@gmail.com.

Resumo: O Rio Jaguaribe é um curso d’água que se situa em João Pessoa-PB, sendo o maior rio da cidade, e vem sofrendo várias formas de degradações ambientais, como resultado de ações das populações que residem às margens do rio, da ausência de um saneamento básico adequado e construção de empreendimentos comerciais as suas margens, merecendo destaque o Shopping Manaíra. Neste sentido, este estudo apresenta como objetivo analisar a relação conflituosa sociedade versus meio ambiente, encontrada no percurso do Rio Jaguaribe que compreende o Bairro São José e Manaíra, e identificar os impactos ambientais resultantes deste conflito ambiental. A metodologia consiste numa pesquisa exploratória, ressaltando a base de conhecimento interdisciplinar, utilizando-se enquanto ferramenta uma abordagem qualitativa do fenômeno a ser estudado. Como resultado, foi possível identificar que o rio se encontra numa situação alarmante, totalmente degradado devido ao elevado nível de poluição, retirada da mata ciliar, ocupação irregular das Áreas de Preservação Permanente (APP), constituindo um risco ao ecossistema aquático, assim também como à saúde pública da comunidade São José, resultado da ausência de conscientização ambiental e descaso dos órgãos públicos responsáveis.

Palavras-chave: Rio Jaguaribe. Meio ambiente. Conflito ambiental.

\section{CASE STUDY OF MANAÍRA MALL EXPANSION AND THE COMMUNITY SÃO JOSÉ OVER THE JAGUARIBE RIVER IN JOÃO PESSOA - PB}

Abstract: The Jaguaribe River is a watercourse that is located in João Pessoa, the largest river of the city and has undergone various forms of environmental degradation as a result of actions of people living along the river, the lack of a adequate sanitation and construction of commercial developments on its banks, with emphasis Shopping Manaíra. Thus, this study has the objective of analyzing the relationship confrontational society versus the environment, found in Jaguaribe River route comprising the Neighbourhood Joseph and Manaíra, and

\section{POLÊM!CA | LABORË:}

Polêmica - Revista Eletrônica da Uerj - Rua São Francisco Xavier, 524, $1^{\circ}$ andar bloco D, sl.1001 • Tels.: +55 21 2334-4088 / 4087 • http://www.e-publicacoes.uerj.br/index.php/polemica/index http://www.labore.uerj.br • laboreuerj@yahoo.com.br 
identify the environmental impacts of this environmental conflict. The methodology consists of an exploratory research, emphasizing the interdisciplinary knowledge base, using as a tool for qualitative approach of the phenomenon being studied. As a result, it observed that the river is an alarming situation, totally degraded due to the high level of pollution, removal of riparian vegetation, irregular occupation of Permanent Preservation Areas (APP), constituting a risk to the aquatic ecosystem, so as public health community of St. Joseph, a result of the lack of environmental awareness and indifference of the responsible government agencies.

Keywords: Rio Jaguaribe. Environment. Environmental conflict.

\section{Introdução}

A apropriação da natureza pelo ser humano tem gerado impactos negativos ao meio ambiente físico com danos muitas vezes irreversíveis. Dornelles (2006) afirma que o ser humano com o objetivo de atender suas necessidades tem intervindo nos recursos naturais, promovendo acentuadas modificações espaciais ao longo do tempo, comprometendo a sustentabilidade e a existência do próprio homem.

A mancha urbana avançando sobre os espaços naturais amplia os níveis de degradação ambiental, que provoca forte pressão exercida por parte do ser humano sobre os recursos naturais com o uso inadequado dos mesmos, provocando desequilíbrio na relação do ser humano com o meio natural. Os impactos ambientais são decorrentes da poluição e degradação ambiental, causada em grande parte pelas ações humanas sobre o ambiente, e correspondem às alterações das propriedades físicas, químicas ou biológicas dos elementos naturais, implicando ainda em prejuízos a saúde do homem, à sociedade e aos recursos naturais renováveis (ALVES et al 2012).

Muitos impactos ambientais podem ser observados nas áreas urbanas e neste intuito podem-se destacar os recursos hídricos que sofrem graves pressões, sobretudo em virtude do elevado nível de urbanização e industrialização, que em muitos casos ocorre de forma inadequada comprometendo a qualidade dos ecossistemas localizados nas cidades. Borcardim (2008) aponta que os rios urbanos, no âmbito dos municípios, recebem todas as alterações e impactos causados pelas atividades antrópicas, existindo a crescente necessidade de apresentar soluções e estratégias que minimizem e revertam os efeitos dessa degradação ambiental.

Além disso, de acordo com Tucci (2001), o desenvolvimento urbano produz um ciclo de contaminação gerado pelos efluentes da população urbana, como esgoto doméstico, industrial e esgoto pluvial que são as principais fontes de poluição das águas urbanas.

Esta realidade é evidenciada no rio Jaguaribe, que está inserido no ambiente urbano, município de João Pessoa-PB, corta vários bairros da cidade e encontra-se totalmente

\section{POLÊM!CA $\mid$ LABORE}

Polêmica - Revista Eletrônica da Uerj - Rua São Francisco Xavier, 524, $1^{\circ}$ andar bloco D, sl.1001 • Tels.: +55 21 2334-4088 / 4087 • http://www.e-publicacoes.uerj.br/index.php/polemica/index http://www.labore.uerj.br • laboreuerj@yahoo.com.br 
degradado em virtude de ações antrópicas mal planejadas, demonstrando o descaso da sociedade perante sua importância histórica que está intrinsecamente ligada a esse corpo hídrico.

Neste contexto, através dessa pesquisa buscou-se compreender o conflito ambiental existente neste ecossistema aquático localizado entre a comunidade São José e bairro Manaíra, buscando entender as implicações para este recurso hídrico causadas pela população da comunidade que ocupa as margens do rio e a expansão do shopping Manaíra, que desde a sua construção provocou sérias modificações e degradações ao rio.

A relevância do tema proposto consiste no fato de que os conflitos ambientais denunciam as contradições e injustiças que permeiam a sociedade, fruto sobretudo de um sistema capitalista altamente excludente, e compreendê-los é uma forma de denunciar situações gravíssimas em que o poder público se faz omisso e, assim, buscar soluções e alternativas viáveis, alicerçadas nos princípios de sustentabilidade e justiça ambiental.

Zhouri \& Laschefski (2010) enfatizam que a “análise dos conflitos ambientais leganos portanto, a possibilidade de reconhecer os múltiplos projetos de sociedade que acionam distintas matrizes de produção material e simbólica e esbarram nas reais assimetrias das dinâmicas sociais e políticas” (p. 5).

Como metodologia utilizou-se a abordagem de pesquisa exploratória, ressaltando a base de conhecimento interdisciplinar, utilizando-se uma abordagem qualitativa do fenômeno a ser estudado.

\section{Aspectos Metodológicos}

No que se refere aos aspectos metodológicos, foi utilizado o método de pesquisa exploratória, que consiste em uma abordagem específica que corresponde a um estudo de caso, onde se busca, neste formato de pesquisa desenvolvida, apresentar uma caracterização (que neste caso insere-se mediante a premissa de análise de conflito ambiental), categorização e definições acerca do fato (GIL, 2008).

Deste modo, utiliza-se enquanto base de construção do conhecimento, uma abordagem interdisciplinar, visando apreensão da complexidade que está inserida no contexto das questões ambientais, onde a interdisciplinaridade estende dessa maneira seu campo de intervenção “entre disciplinas científicas” para promover o intercâmbio, inter-relação e articulação entre as disciplinas, saberes e práticas, pela intensidade das trocas entre os

\section{POLÊM!CA $\mid$ LABORE}

Polêmica - Revista Eletrônica da Uerj - Rua São Francisco Xavier, 524, $1^{\circ}$ andar bloco D, sl.1001 • Tels.: +55 21 2334-4088 / 4087 • http://www.e-publicacoes.uerj.br/index.php/polemica/index http://www.labore.uerj.br • laboreuerj@yahoo.com.br 
especialistas e pelo grau de interação real destas no interior de um mesmo projeto (JAPIASSU, 1978; PHILIPPI Jr, 2000).

Com isso, na busca de um delineamento para a pesquisa desenvolve-se nesta uma abordagem qualitativa, de cunho bibliográfico, objetivando apresentar uma caracterização do espaço em estudo, ao mesmo tempo que identificando seus respectivos atores sociais e as suas inter-relações através de um estabelecimento de uma rede de relações e conflitos. Sendo que segundo Chizzotti (1995, p.79), tem-se na abordagem qualitativa parte do fundamento de que há uma relação dinâmica entre o mundo real e o sujeito, uma interdependência viva entre o sujeito e o objeto, um vínculo indissociável entre o mundo objetivo e a subjetividade do sujeito. Assim sendo, busca-se não uma abordagem isolada das variáveis (neste caso os atores que formulam o cenário de conflito ambiental), mas sim o estabelecimento das relações permeada por estes atores.

\section{Caracterização da área de pesquisa}

O estudo foi desenvolvido no município de João Pessoa que se apresenta enquanto capital do Estado da Paraíba, localizada na mesorregião da Mata Paraibana e na microrregião que leva o nome da referida unidade municipal. Quanto a sua localização longitudinal e latitudinal, está situada $07^{\circ} 05^{\prime} 00^{\prime \prime}$ de latitude Sul e 34 50' 00" longitude Oeste, e altitude de 40 metros em relação ao Nível Médio do Mar (NMM). Assim, ao que se refere a sua vizinhança, este se limita com os municípios de Cabedelo ao Norte, Bayeux e Santa Rita a Oeste, Conde ao Sul e ao Leste com Oceano atlântico (Mapa 1).

O município de João Pessoa possui uma área correspondente a uma população de 723.515 habitantes e com um território de 211,475 km², resultando numa densidade demográfica de 3.421,28 hab./ $\mathrm{km}^{2}$ segundo o censo demográfico realizado pelo Instituto Brasileiro de Geografia e Estatística - IBGE (2010).

Mapa - 1: Localização Geográfica do Município de João Pessoa-PB e sua área de Entorno

\section{POLÊM!CA $\mid$ LABORE}




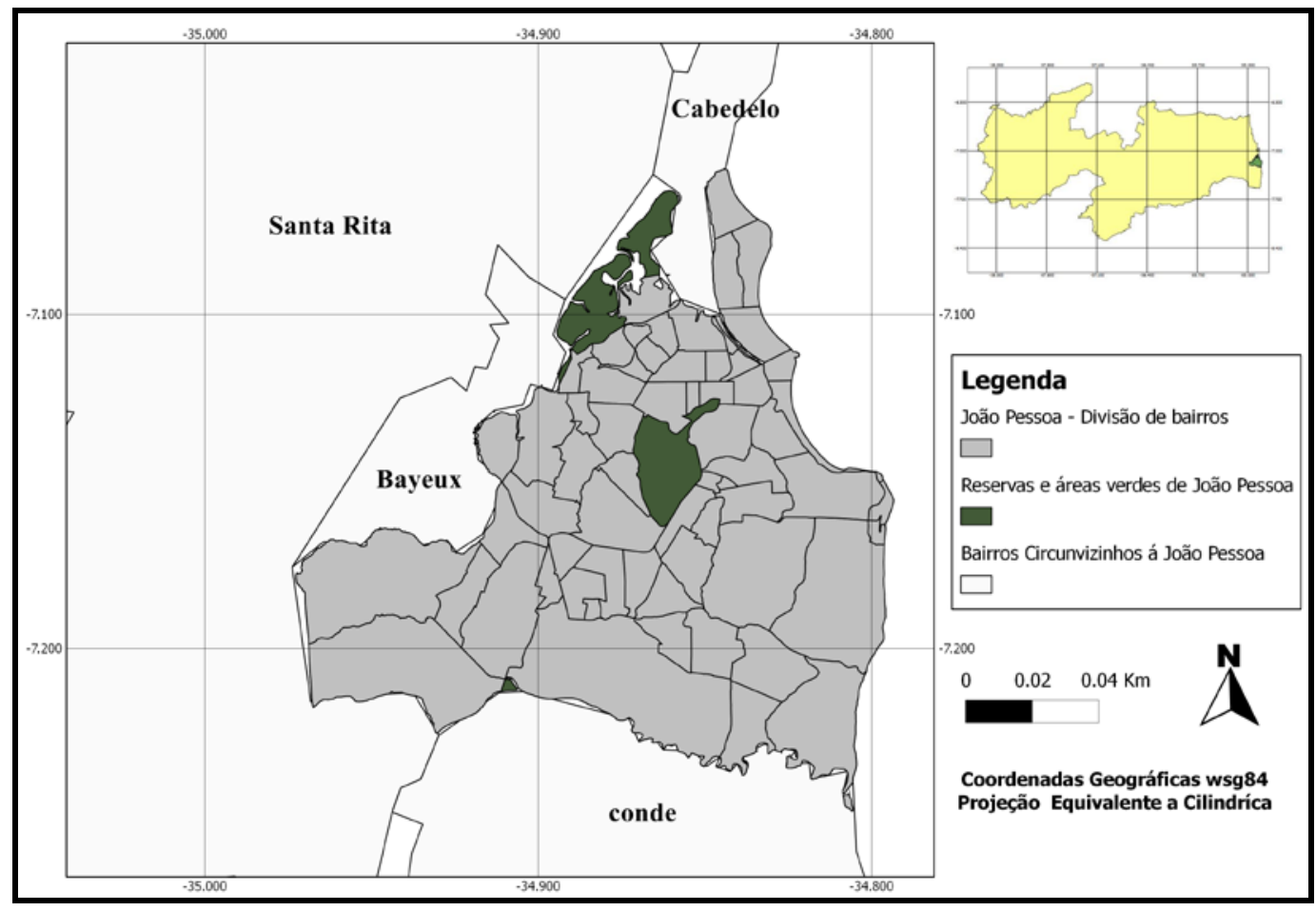

Fonte: Josué Barreto da S. Júnior, 2013.

Assim sendo, observa-se a configuração da maior região metropolitana do Estado da Paraíba, a região Metropolitana de João Pessoa, que se configura por uma junção da capital paraibana e de outros 10 municípios, o que faz com que tal região tenha uma população superior a um milhão de habitantes (1 milhão e 150 mil habitantes). No tocante aos aspectos sociais e econômicos, o município monopoliza setores que ultrapassam as perspectivas demográficas, tendo além destes a maior demografia, economia, Índice de Desenvolvimento Humano (IDH), Produto Interno Bruto (PIB), entre outros. Desta forma, João Pessoa concentra 30,7\% das riquezas produzidas na Paraíba, e possui o maior IDH do estado, com 0,763 .

Quanto a caracterização climática, João Pessoa apresenta clima tropical úmido, possuindo temperatura média de $25^{\circ} \mathrm{C}$ e com alta umidade relativa do ar (correspondente a 80\% anuais). E quanto a sua vegetação consiste na Mata Latifoliada Perenifólia Costeira mais conhecida como Mata Atlântica, bastante degradada atualmente.

Em relação aos fatores hidrogeográficos do município, observa-se a presença de forma efetiva de grande quantidade de rios cortando todo o território municipal, sendo que dos doze rios presentes no espaço, destaca-se o rio Jaguaribe, que tem a sua nascente localizada no bairro “Esplanada”, desaguando antigamente na praia do Bessa, porém, com a presença de

\section{POLÊM!CA $\mid$ LABORẸ}

Polêmica - Revista Eletrônica da Uerj - Rua São Francisco Xavier, 524, $1^{\circ}$ andar

bloco D, sl.1001 • Tels.: +55 21 2334-4088 / 4087 • http://www.e-publicacoes.uerj.br/index.php/polemica/index

http://www.labore.uerj.br • laboreuerj@yahoo.com.br 
empreendimentos, tem-se em 1931 a transferência do rio para o Rio Mandacaru, onde o rio passa a desaguar no estuário do rio Paraíba, mais precisamente na divisa com Cabedelo. Com isso, compreende-se o Rio Jaguaribe enquanto um rio urbano, sendo que este corta todo o perímetro urbano de João Pessoa e tem como principal afluente o Rio Timbó. A bacia está situada em uma área sedimentar, situada em zonas de ordem Subcosteira e Costeira, com extensão de 21 km. Com isso a área em análise está localizada especificamente na região de baixo curso do Rio, com altitude de $11 \mathrm{~m}$. (Mapa 2).

Mapa - 2: Localização do Conflito Ambiental na Bacia do Rio Jaguaribe em João Pessoa

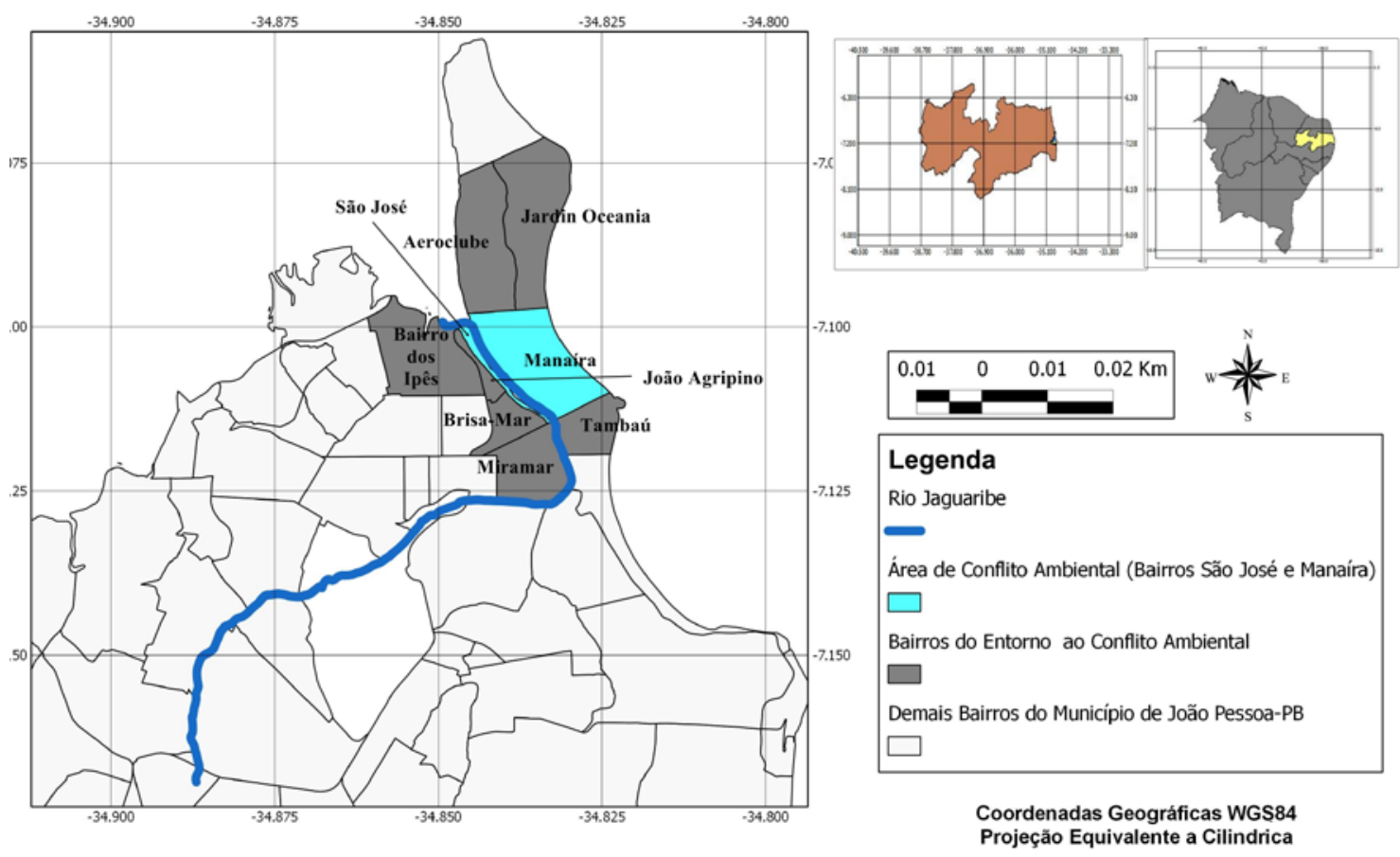

Fonte: Josué Barreto da Silva Júnior, 2013.

Com aproximadamente 13.000 habitantes, situado na cidade de João Pessoa, o bairro São José se enquadra numa realidade de comprometimento socioambiental. O bairro surgiu como um assentamento espontâneo informal desordenado de migrantes de baixo poder

\section{POLÊM!CA $\mid$ LABORE}

Polêmica - Revista Eletrônica da Uerj - Rua São Francisco Xavier, 524, $1^{\circ}$ andar bloco D, sl.1001 • Tels.: +55 21 2334-4088 / 4087 • http://www.e-publicacoes.uerj.br/index.php/polemica/index http://www.labore.uerj.br • laboreuerj@yahoo.com.br 
aquisitivo que ocuparam sem licença todo o vale às margens do rio Jaguaribe (consideradas Área de Preservação Permanente - APP) e próximo as encostas, acarretando graves prejuízos sociais e ambientais, levando a uma baixa qualidade de vida para os moradores e sérias agressões ao meio ambiente. Lima (2006) confirma tal realidade ao afirmar que a comunidade São José, é um bairro com características de favela, ocupação desordenada e em áreas de risco ambiental, precariedade das moradias, insalubridade, sem espaços de sociabilidade, alta densidade construtiva e condições de habitabilidade inalcançáveis, bem como formato de topografia imprópria para o estabelecimento de moradias.

Um aspecto interessante é que a comunidade está cercada por bairros considerados 'nobres' (principalmente Manaíra e João Agripino), ficando localizado ao lado do maior e mais importante shopping Center da cidade, evidenciando assim uma segregação socioespacial, com a presença do isolamento dos pobres da comunidade São José e a presença do processo de fortificação da área física do Shopping Center.

O Manaíra Shopping é o primeiro e principal do segmento na região sendo o maior do Estado, construído no bairro que tem o mesmo nome (Bairro Manaíra). A construção do empreendimento teve início no ano de 1987 e foi concluído dois anos depois.

Desde o seu processo de construção há uma polêmica que envolve a relação economia versus meio ambiente, pois o shopping localiza-se as margens do Rio Jaguaribe (ver a Foto 1 A), e atualmente acrescenta-se “novos capítulos” tendo em vista o processo de expansão do mesmo durante o ano de 2013 (Ver a figura 1 B).

Foto - 1: A; B: Início do processo de construção do Shopping Manaíra em 1987; processo de Aterramento do Rio Jaguaribe e expansão do Setor de Estacionamento do Shopping Manaíra.
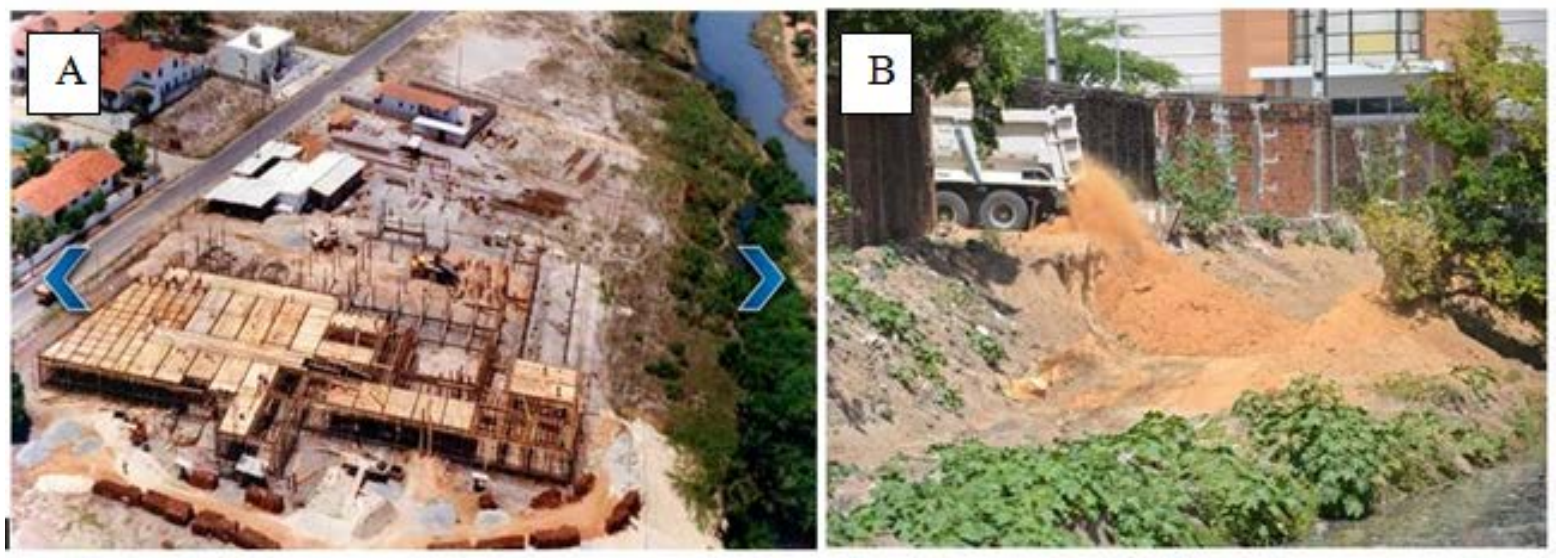

Fonte: G1-PB.

\section{POLÊM!CA | LABORE}

Polêmica - Revista Eletrônica da Uerj - Rua São Francisco Xavier, 524, $1^{\circ}$ andar bloco D, sl.1001 • Tels.: +55 21 2334-4088 / 4087 • http://www.e-publicacoes.uerj.br/index.php/polemica/index http://www.labore.uerj.br • laboreuerj@yahoo.com.br 
O Shopping Manaíra apresenta-se com uma estrutura de 292 lojas satélites e 16 do tipo Âncora, dispondo também de 8 salas de cinema, pista para boliche, bem como de uma casa de show com capacidade para 15.000 pessoas. Possui uma área construída de $115 \mathrm{mil} \mathrm{m²}$ e estacionamento para 6.000 vagas.

Ainda está em processo de expansão de construção em sentido vertical. O Shopping, que tem como Slogan "Sempre Pensando em você" e nunca no meio ambiente, a cada ano busca os mais audaciosos planos de expansão, até mesmo através do aterramento ilegal do Rio Jaguaribe e fortificação tendo em vista que o mesmo está situado ao lado da comunidade São José, que apresenta um elevado grau de vulnerabilidade social e econômica e elevado índice de violência.

\section{Revisão de Literatura}

\section{Expansão urbana e os recursos hídricos}

A urbanização como fenômeno mundial é tanto um fato recente quanto crescente, pois por volta de meados do século XIX a população urbana representava $1,7 \%$ da população total do planeta, atingindo em 1960 (um século depois) 25\%; em 1980 esse número passou para 41,1\% (SANTOS, 1981). No Brasil, a urbanização ganha força a partir de 1950, com o advento da industrialização, onde as pessoas passaram a sair do campo para a cidade em busca de melhores condições de vida, através de empregos oferecidos pelas indústrias. Já nos anos 80, o ritmo de crescimento da população nas cidades apresentou uma desaceleração, mas mesmo assim fez com que a sua participação chegasse a 84\% do total do país no ano 2010 (IBGE, 2010).

Esta expansão observada ao longo dos tempos tem colocado as populações urbanas como as maiores responsáveis por grandes alterações ambientais. "Este processo tem provocado alterações significativas no meio ambiente, alterando a qualidade de alguns suprimentos vitais oferecidos ao homem tais como: ar fresco, água potável, alimento, espaços de lazer, dentre outros” (NETO et al, p.3, 2007).

Agra Filho (2008) aponta que a problemática ambiental contemporânea se origina dos usos conflitantes gerados tanto pelas diversas demandas da sociedade em relação a um

\section{POLÊM!CA $\mid$ LABORE}


determinado recurso ou sistema ambiental quanto pelas próprias alterações das condições ambientais. Logo, existem sérios conflitos ambientais no meio urbano. De um lado tem-se uma população que não tem consciência das implicações de suas ações sobre o meio ambiente que resulta na degradação do mesmo, e de outro lado ocorre a utilização dos recursos naturais para fins de desenvolvimento econômico. Conforme ainda ressalta Agra Filho (2008), os conflitos ocorrem ainda quando uma determinada atividade econômica ameaça determinadas áreas com importantes atributos ecológicos ou ecossistemas sensíveis que são protegidos legalmente.

Mendonça (2002) afirma que a fase mais contemporânea da modernidade caracteriza-se por uma intensa complexidade das relações sociais e destas com a natureza. A relação conflituosa estabelecida entre a sociedade e o meio natural gerou consideráveis problemas socioambientais nos últimos duzentos anos, sobretudo em virtude da pressão exercida sobre os recursos naturais, de modo que a degradação ambiental das cidades é alarmante.

São visíveis os problemas ambientais decorrentes desse processo de urbanização. Para fins deste estudo, destaca-se a problemática dos recursos hídricos nas áreas urbanas, que ocorre em virtude de vários fatores. Um dos principais agravantes é a contaminação das águas, que ocorre principalmente devido ao lançamento de esgotos sem tratamento, despejo de resíduos sólidos, ocupação de áreas de preservação, afetando de forma direta os mananciais, resultado da ausência de infraestrutura, planejamento no uso do solo e a falta de políticas públicas eficientes e eficazes.

Braga e Carvalho (2003) comentam que o quadro de desequilíbrio dos recursos hídricos urbanos e os problemas ambientais, associados às enchentes e à deterioração da qualidade das águas, resultam não só do lançamento de esgoto doméstico, mas também da ocupação inadequada do solo nas bacias urbanas.

\section{Gestão dos recursos hídricos e Legislação Ambiental}

As bacias hidrográficas tem sido adotadas como unidades de análise, planejamento e gerenciamento ambiental, onde se é possivel a avaliação dos processos e integrações presentes, e todos os elementos (físicos, biológicos e sociais) se relacionam entre si. Numa bacia é possível avaliar de forma integrada as ações humanas sobre o ambiente e seus desdobramentos sobre o equilíbrio hidrológico (BOTELHO \& SILVA 2008).

\section{POLÊM!CA $\mid$ LABORE}


As bacias hidrográficas sofrem forte influência de ações antrópicas mal planejadas que degradam este recurso natural, sobretudo nas áreas urbanas, e diante disso surge a necessidade de um manejo integrado e de seu gerenciamento, consistindo isto em um instrumento essencial para um controle do uso dos recursos hídricos, de maneira a orientar as ações pertinentes para o uso racional deste recurso, visando o desenvolvimento sustentável.

A gestão de recursos hídricos é definida como o conjunto de ações destinadas a regular o uso, o controle e a proteção deste recurso em conformidade com a legislação e normas pertinentes. Integra projetos e atividades com o objetivo de promover a recuperação e a preservação da qualidade e quantidade dos recursos das bacias hidrográficas brasileiras e atua na recuperação e preservação de nascentes, mananciais e cursos d'água em áreas urbanas (AESA, 2012).

A Lei Federal nº 6.938/81, que dispõe sobre a Política Nacional do Meio Ambiente, nos termos do art. $8^{\circ}$, destaca que compete ao CONAMA (Conselho Nacional do Meio Ambiente) “estabelecer normas, critérios e padrões relativos ao controle e à manutenção da qualidade do meio ambiente com vistas ao uso racional dos recursos ambientais, principalmente os hídricos”. Sendo assim, compete a Resolução do CONAMA 303/02, estabelecer os parâmetros, definições e limites referentes às áreas de preservação permanente, ou seja, parâmetros de controle de limites das matas ciliares, próximas aos rios e mananciais (CONAMA, 2002).

Na década de 1990, foi promulgada a Lei Federal $n^{\circ} 9.433$ que instituiu a Política Nacional de Recursos Hídricos, criando o Sistema Nacional de Gerenciamento de Recursos Hídricos, e regulamentou o inciso IX do Artigo 21 da Constituição Federal (BARBOSA, 2007). Esta lei concentra seus fundamentos em objetivos, diretrizes e instrumentos para gestão hídrica no Brasil, que estabelece claramente que a água torna-se um bem de domínio público.

Para Araújo (2011), este fato é um vetor importante por possibilitar a reforma dos processos de tomada de decisão, migrando do paternalismo, clientelismo para uma prática democrática participativa, e por possibilitar, também, a organização de um sistema institucional especializado na questão dos recursos hídricos.

Souza Filho (2011) afirma que a transparência e o controle social do gerenciamento de recursos hídricos são importantes e devem ser promovidos, onde a construção de mecanismos de disseminação da informação como portais e ferramentas que viabilizem sua

\section{POLÊM!CA $\mid$ LABORE}

Polêmica - Revista Eletrônica da Uerj - Rua São Francisco Xavier, 524, $1^{\circ}$ andar bloco D, sl.1001 • Tels.: +55 21 2334-4088/4087 • http://www.e-publicacoes.uerj.br/index.php/polemica/index http://www.labore.uerj.br • laboreuerj@yahoo.com.br 
disponibilidade para esses mecanismos deve ser elaborada para viabilizar a transparência e o controle social do processo.

$\mathrm{O}$ art. $2^{\circ}$, da Lei Federal no 4.771 (Código Florestal Brasileiro, de 15 de setembro de 1965), define os limites de Área de Preservação Permanente (APP), conforme o tamanho do leito do corpo hídrico. No caso rio Jaguaribe, no espaço de estudo, a área de APP, dever ser de $50 \mathrm{~m}$, pois o mesmo possui um leito de aproximadamente 20 metros de largura.

\section{Resultados e Discussão}

A partir da pesquisa exploratória foi possível verificar, na área do Rio Jaguaribe, em seu percurso entre o Bairro Manaíra e comunidade São José na cidade de João Pessoa, sérios impactos ambientais sobre este manancial.

Impacto ambiental é “qualquer alteração das propriedades físicas, químicas e biológicas do meio ambiente, causadas por qualquer forma de matéria ou energia resultante das atividades humanas que direta ou indiretamente afetam” (CONAMA, 2002). Este conceito é totalmente válido para a localidade em questão que atualmente se encontra degradada e impactada de forma negativa devido às ações antrópicas desenvolvidas no local.

Além disso, a proteção legal dessa área, em todos os âmbitos, ou seja, na esfera Federal (Código Florestal, lei $n^{\circ}$ 4.771, 15.09.1965), Estadual (Constituição Estadual de 1989) e Municipal (Código de Urbanismo de 1975, a área está inserida em uma Zona Especial de Preservação, Art.39 do Plano Diretor), está sendo totalmente infringida, tendo em vista o cenário degradante, a omissão do poder público para minimizar ou mitigar os impactos ambientais sobre o Rio. Alves et. al (2009) afirmam que os entes governamentais, membros de órgãos públicos e a população em geral são tão culpados quanto os efetivos degradadores desses ecossistemas, pois se omitem diante do problema gerando uma sensação de impunidade.

Deste modo, em observação e análise dos instrumentos legais, está claramente configurado um conflito ambiental, de uso e ocupação do solo da área estudada. Destacam-se dois fatores preponderantes que levaram à degradação do Rio Jaguaribe: a expansão e ocupação desordenada pela população de baixa renda (aglomerados subnormais) da comunidade São José nas margens do rio e a construção e ampliação do Shopping Manaíra sobre o mesmo.

\section{POLÊM!CA $\mid$ LABORE}

Polêmica - Revista Eletrônica da Uerj - Rua São Francisco Xavier, 524, $1^{\circ}$ andar bloco D, sl.1001 • Tels.: +55 21 2334-4088 / 4087 • http://www.e-publicacoes.uerj.br/index.php/polemica/index http://www.labore.uerj.br • laboreuerj@yahoo.com.br 


\section{Ocupação desordenada pela população de baixa renda: Comunidade São José}

O intenso processo de ocupação e urbanização sofrido nas últimas décadas no vale do Jaguaribe causou profundas alterações no ecossistema aquático, de modo que ele vem sendo degradado ao longo dos anos, tendo como um dos principais agravantes a ocupação irregular de aglomerados subnormais ou favelas.

O rio Jaguaribe atraiu um grande contingente populacional devido a disponibilidade de elementos essenciais a sobrevivência humana (água e lenha) que acarretou a ocupação de suas margens e resultou em uma área de risco para a população, implicando em sérios problemas sociais e ambientais.

Os principais tipos de impactos/problemas ambientais causados pela população ribeirinha que estão contribuindo para a degradação do Rio Jaguaribe e suas margens são: deposição de lixo nas margens e na bacia do rio, lançamento de esgoto doméstico que atinge as águas superficiais e subsuperficiais, retirada da mata ciliar e descaracterização da cobertura vegetal.

A população do bairro que reside às margens do rio, conhecido como "Beira do rio", tem o manancial como seu quintal, e pela ausência de uma conscientização ambiental, depositam seus resíduos sólidos no rio (Foto 2), poluindo e contaminando o solo, a água e ocasionando uma poluição visual estarrecedora, pois em muitos pontos é possível identificar a formação de pequenos lixões nas margens do rio e sob o ponto de vista ambiental, os lixões podem causar poluição das águas superficiais e subterrâneas, devido à percolação do chorume, que é um líquido altamente poluente, formado da degradação da matéria orgânica não-controlada, além da poluição atmosférica (PEREIRA, 2009, p 86).

Essa situação eleva o nível de degradação do ambiente devido à diversidade e quantidade de resíduos sólidos que foram observados: papéis, latas, madeiras, plásticos, vidros, restos de alimentos, utensílios domésticos, roupas, móveis, eletrodomésticos, entre outros.

Foto - 2: A e B: Resíduos sólidos.
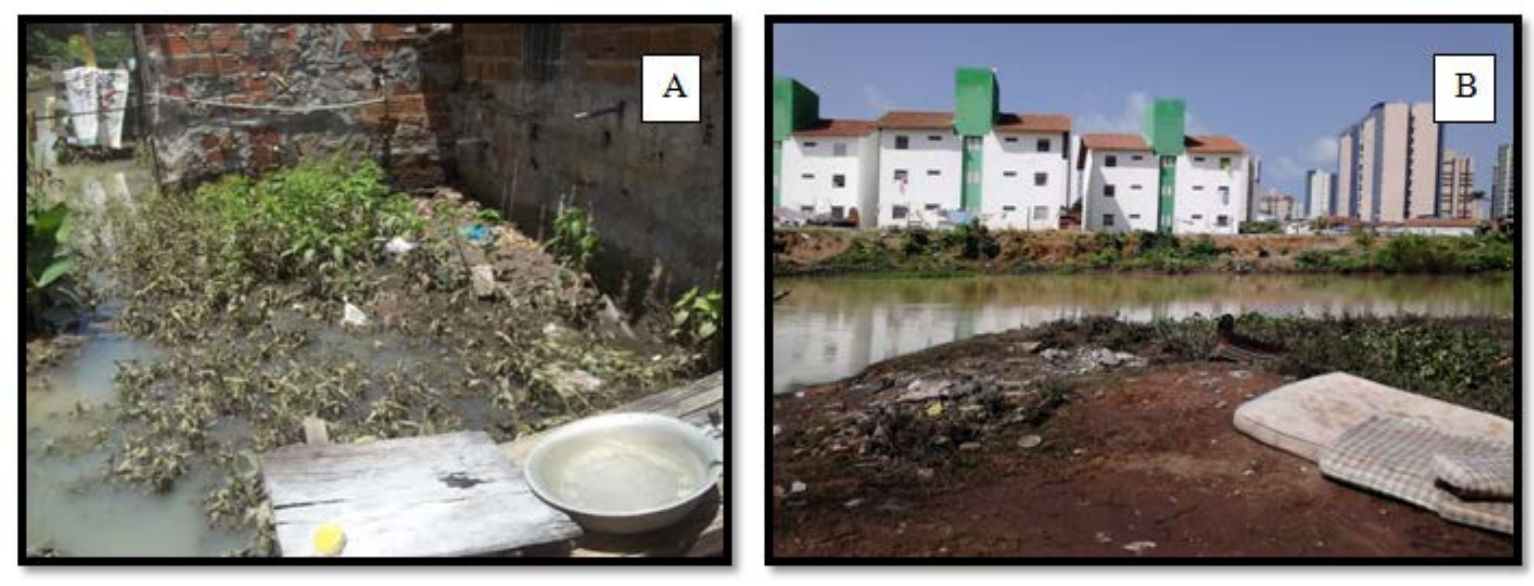
Fonte: Monalisa Cristina Silva Medeiros (2015).

Com relação ao lançamento de esgoto doméstico, caracteriza-se como uma problemática séria, pois o esgoto dessas casas é canalizado diretamente para o rio (Foto 3), elevando o nível de poluição dessas águas, que hoje é totalmente imprópria para qualquer tipo de atividade humana, pois infelizmente funciona como um esgoto a céu aberto, tendo em vista que o rio recebe o esgoto de vários bairros. As informações mencionadas são preocupantes, uma vez que esta situação indica a ausência ou a defasagem de saneamento básico, e este elemento está diretamente ligado a questões de saúde humana e de qualidade de vida.

Foto - 3: A e B: Esgoto canalizado para o rio

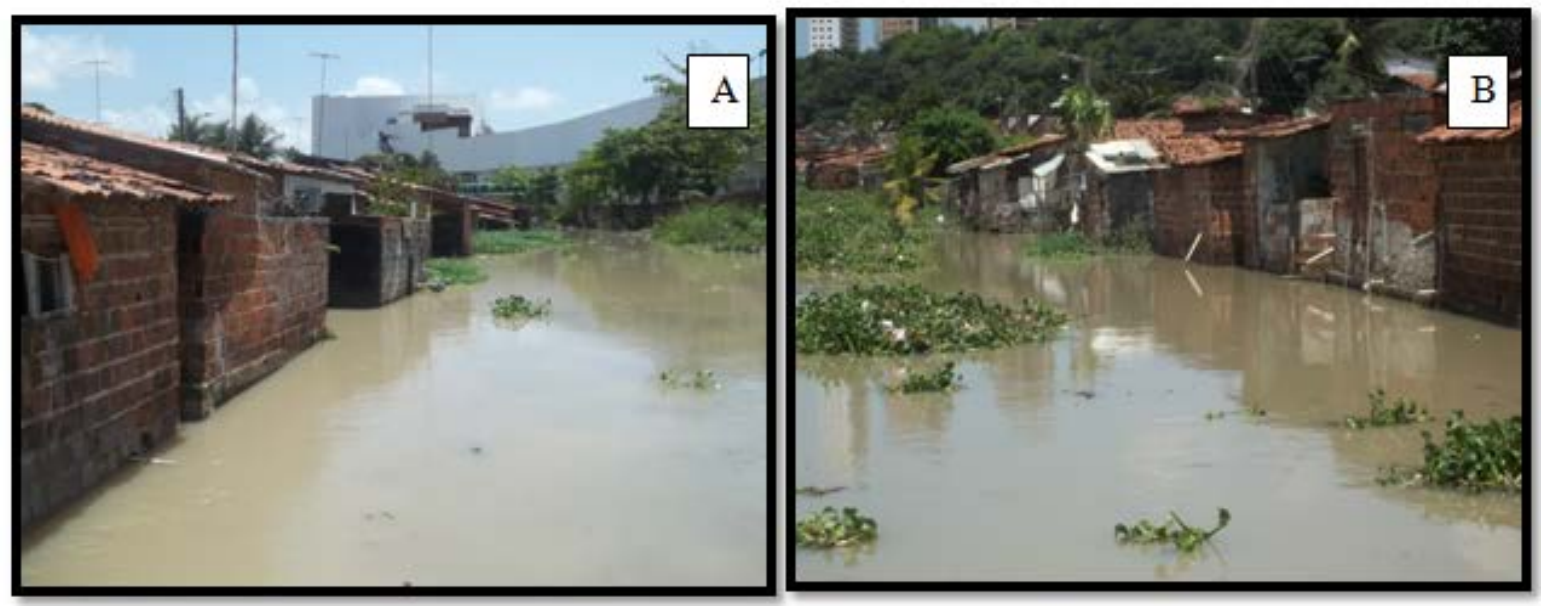

Fonte: Monalisa Cristina Silva Medeiros (2015).

Alves (2012) lembra que a Lei 11.445 de 5 de janeiro de 2007, denominada Lei do Saneamento Básico, estabelece diretrizes nacionais para o saneamento básico e institui a Política Federal de Saneamento Básico, que tem como primeiro objetivo a universalização do acesso ao saneamento básico, abrangendo a zona urbana e a zona rural dos municípios. O saneamento básico é um dos principais indicadores da qualidade de vida e do desenvolvimento econômico e social de uma cidade.

Na comunidade São José, observa-se a precarização do saneamento básico e, além disso, a poluição juntamente com as intempéries das condições climáticas (inundações) trazem prejuízos materiais a esta comunidade, assim também como constituiu risco à saúde pública pelo contato direto com a água poluída, convivendo em ambiente insalubre, resultado da ausência de conscientização ambiental e descaso dos órgãos públicos responsáveis.

\section{POLÊM!CA | LABORẸ}

Polêmica - Revista Eletrônica da Uerj - Rua São Francisco Xavier, 524, $1^{\circ}$ andar bloco D, sl.1001 • Tels.: +55 21 2334-4088 / 4087 • http://www.e-publicacoes.uerj.br/index.php/polemica/index http://www.labore.uerj.br • laboreuerj@yahoo.com.br 
Outro problema identificado é a proliferação da Eicchornia Crassipes, que é a pasta encontrada sobre a superfície das águas (Foto 4), conhecida como “Aguapé ou Baronesa”. Devido à imensa capacidade de absorção de nutrientes, possui grande utilidade na despoluição de esgotos, por isso é muito comum encontrar o aguapé em águas poluídas, pois nestes locais existe abundância de alimento, mas em situações de superpopulação ela pode se tornar um problema, por não permitir a oxigenação da água e seus organismos, e quando ocorrem chuvas torrenciais, a pasta juntamente com o lixo acaba obstruindo a passagem da água (MEDEIROS, 2013).

Foto - 4: A e B: Proliferação de aguapés
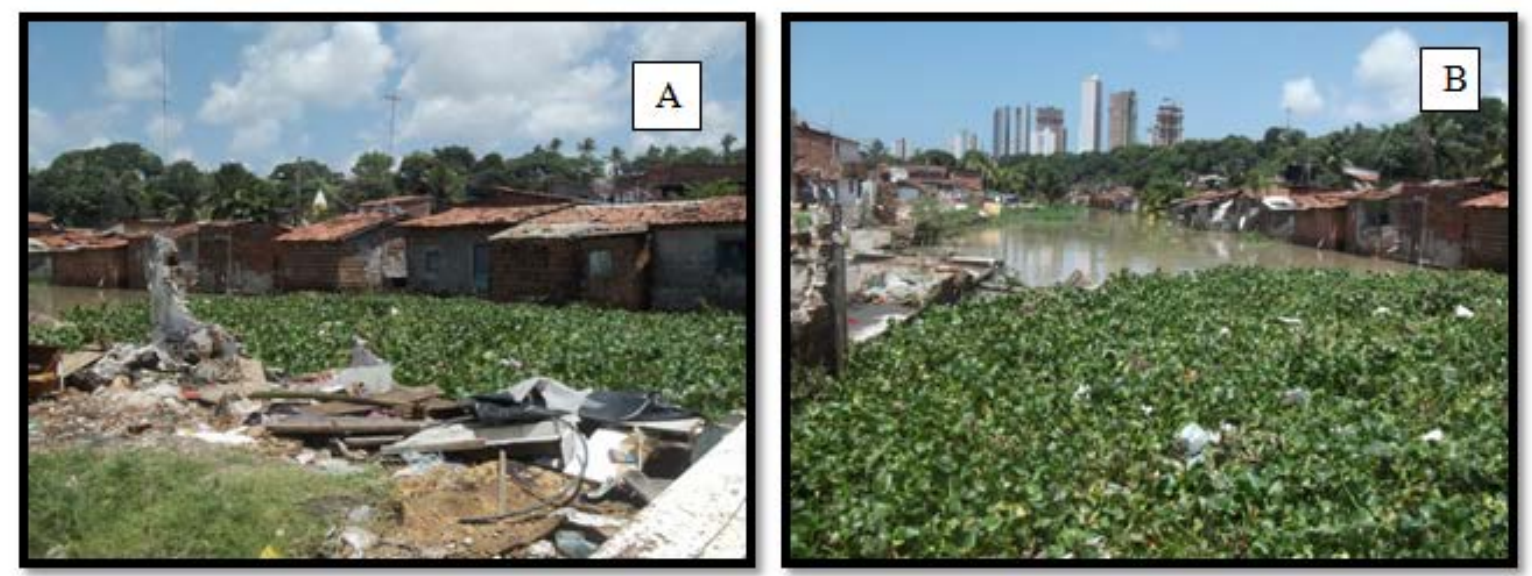

Fonte: Monalisa Cristina Silva Medeiros (2015).

No que concernem à retirada da cobertura da vegetação, este impacto foi identificado em todo percurso do rio. Nas margens não mais existe matas ciliares (vegetação protetora), e isso ocorre porque a área precisa ser desmatada para ocupação e construção das casas. Costa \& Araújo (2012) afirmam que o rio Jaguaribe já apresenta um alto grau de desmatamento; cerca de $80 \%$ de seu curso já não possui nenhum tipo de vegetação.

\section{Construção e ampliação do Manaíra Shopping.}

O Rio Jaguaribe sofreu intervenções agressivas com a construção do complexo empresarial Manaíra Shopping que, com suas edificações e posteriores ampliações, obstruiu o curso natural do rio.

O Manaíra Shopping, localizado no bairro de Manaíra vizinho à comunidade São José, foi inaugurado em 11 de novembro de 1989, gerando grande polêmica por estar sobre uma

\section{POLÊM!CA $\mid$ LABORE}

Polêmica - Revista Eletrônica da Uerj - Rua São Francisco Xavier, 524, $1^{\circ}$ andar bloco D, sl.1001 • Tels.: +55 21 2334-4088 / 4087 • http://www.e-publicacoes.uerj.br/index.php/polemica/index http://www.labore.uerj.br • laboreuerj@yahoo.com.br 
área de mangue (Rio Jaguaribe), desrespeitando as leis ambientais e ocasionando sérios prejuízos ambientais ao ecossistema. É o principal shopping da cidade e considerado um equipamento de atração turística, atraindo não apenas o público da cidade assim também como turistas e visitantes (PREFEITURA MUNICIPAL DE JOÃO PESSOA, 2013).

Desde sua construção, o empreendimento passou por quatro grandes ampliações em 1993, 1997, 2002 e 2007, elevando-o a categoria de segundo maior centro de compras do Nordeste com mais de 10 mil metros quadrados, com grande importância econômica para cidade e região.

Essa ampliação trouxe sérios prejuízos ambientais ao Rio Jaguaribe, pois a primeira fase da ampliação do Shopping foi feita com uma intervenção que desviou um trecho do leito original do Rio Jaguaribe, passando a correr apenas através de um canal por baixo do estacionamento do Shopping. E em etapa seguinte de ampliação, parte do edifício foi feito sobre o rio (COSTA \& ARAÚJO, 2012, p. 123).

A última expansão do shopping foi a ampliação do estacionamento sobre uma área pública situada na faixa mínima de proteção ambiental da margem do rio Jaguaribe (Foto 5), evidenciando o não cumprimento da legislação ambiental vigente, tanto municipal, estadual e federal. O Código Florestal determina a preservação ao longo dos rios ou de qualquer curso d’água desde o seu nível mais alto em faixa marginal cuja largura mínima seja: 1 - de 30m (trinta metros) para os cursos d'água de menos de 10m (dez metros) de largura. Além disso, é extremamente preocupante a cumplicidade e omissão da Prefeitura Municipal de João Pessoa e da Câmara Municipal, e o aval da SUDEMA (Superintendência de Administração do Meio Ambiente).

Foto - 5: A e B: Ampliação do estacionamento sobre o rio

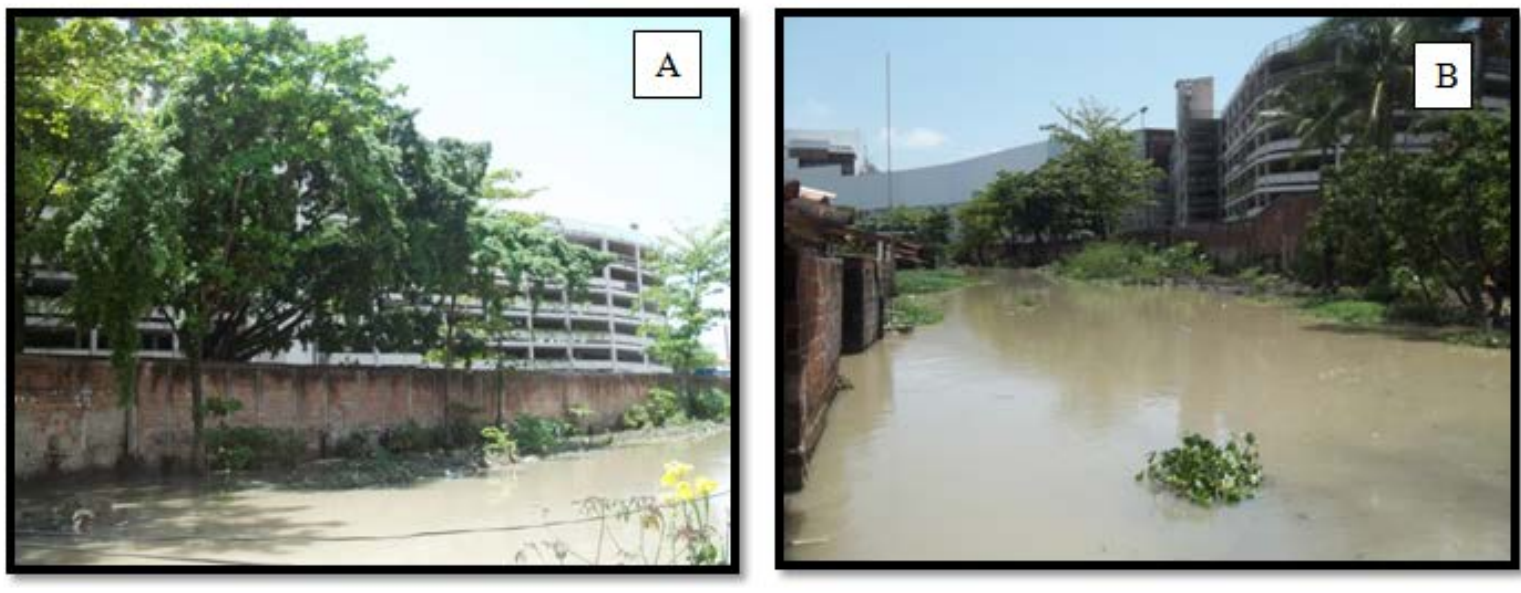

\section{POLÊM!CA $\mid$ LABORE}

Polêmica - Revista Eletrônica da Uerj - Rua São Francisco Xavier, 524, $1^{\circ}$ andar bloco D, sl.1001 • Tels.: +55 21 2334-4088 / 4087 • http://www.e-publicacoes.uerj.br/index.php/polemica/index http://www.labore.uerj.br • laboreuerj@yahoo.com.br 
Fonte: Monalisa Cristina Silva Medeiros (2015).

Esta realidade evidencia perdas ecológicas irreversíveis, pois a interceptação do curso compromete seriamente a sobrevivência do ecossistema. Observa-se, portanto, apenas ganhos aferidos pelo empresário proprietário com a invasão de uma área pública.

Atualmente existe um projeto para uma nova ampliação do estacionamento, mais uma vez sobre o rio, que desde sua última expansão já teve a margem aterrada para este objetivo futuro (Foto 6).

Foto - 6: A e B: Margem do rio aterrada
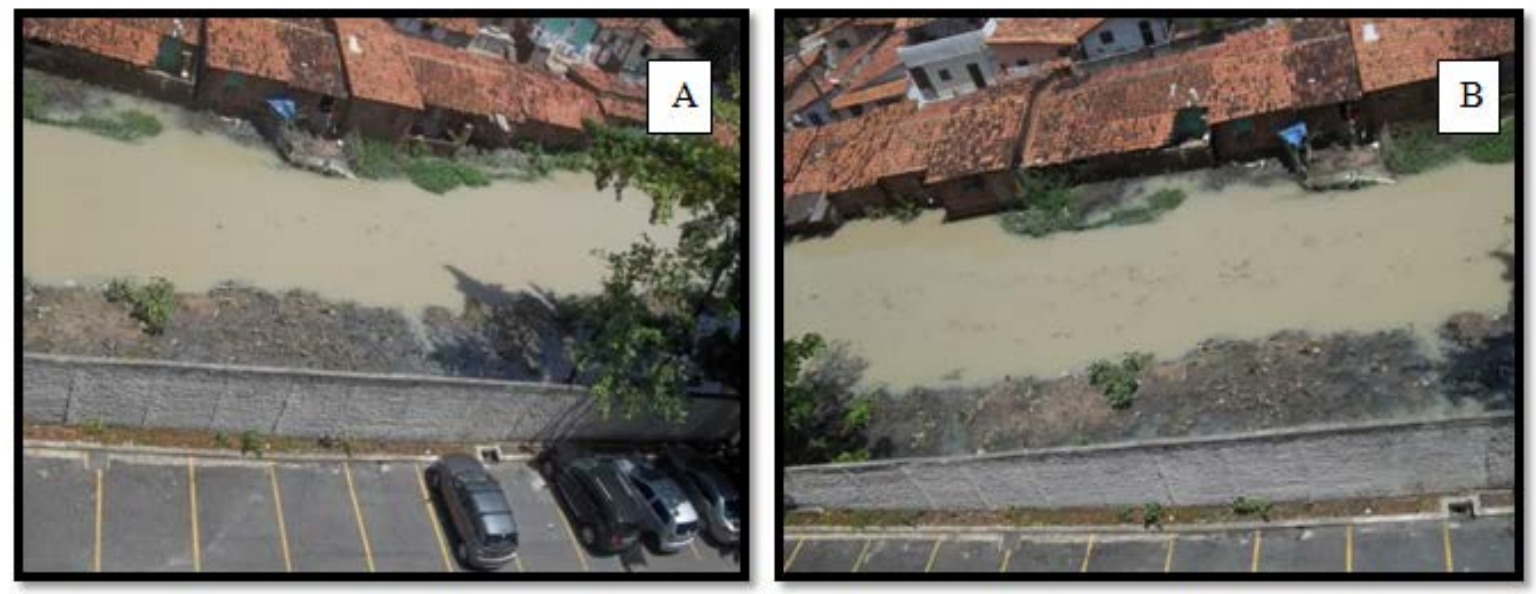

Fonte: Monalisa Cristina Silva Medeiros (2015).

É perceptível o estreitamento do rio com a ampliação do shopping, que força o "enforcamento" do seu leito e inviabiliza o escoamento maior na época das chuvas, provocando as inundações.

Este conflito ambiental mostra a degradação decorrente desta obra, revelando que o fator econômico é preponderante, onde as transformações no meio urbano estão diretamente ligadas aos interesses das elites políticas e econômicas, que não leva em consideração o meio ambiente.

\section{Considerações Finais}

Diante da realidade abordada, compreende-se que a problemática envolvendo o rio Jaguaribe e os atores sociais do seu entorno (comunidade do Bairro São José e o empreendimento Shopping Manaíra) parece não ter uma prenuncia de solução, tendo em vista

\section{POLÊM!CA $\mid$ LABORE}

Polêmica - Revista Eletrônica da Uerj - Rua São Francisco Xavier, 524, $1^{\circ}$ andar bloco D, sl.1001 • Tels.: +55 21 2334-4088 / 4087 • http://www.e-publicacoes.uerj.br/index.php/polemica/index http://www.labore.uerj.br • laboreuerj@yahoo.com.br 
os constantes danos sofridos pelo ambiente ao longo do processo de urbanização de João Pessoa. Desde 1931 constatam-se mudanças circunstanciais na rota do rio Jaguaribe, acarretando complicações ao ecossistema aquático, assim também como a população que reside nas margens e adjacências do mesmo.

Com isso, a Prefeitura Municipal de João Pessoa visa o estabelecimento de um projeto de urbanização da área de baixo curso do Jaguaribe, mais precisamente área que abarca a Comunidade São José, porém antes mesmo da existência de uma aplicabilidade concreta no espaço, o mesmo já desponta com grande polêmica. A população "beneficiada” aponta que a implementação deste projeto vai bem além do caráter mitigatório de problemáticas como enchentes, mas sim favorecimento a empreendimentos e especulação imobiliária que atuam com muita força na região, sendo reivindicado pela comunidade o diálogo com a prefeitura.

No que se refere ao papel do município dentro desta problemática, existe a omissão do poder público (Prefeitura Municipal) e da Secretaria de Meio Ambiente (SUDEMA) ao conceder licenças anteriores para ampliação da estrutura do shopping de forma irregular, burlando leis ambientais, com processo de aterramento das margens, desvio do leito do rio e construção sobre o mesmo, diminuindo a "calha” do rio afetando além do meio ambiente o meio social, com o crescimento da problemática das enchentes na comunidade São José.

De maneira geral, é imprescindível uma ação conjunta por parte dos poderes públicos com a indispensável participação popular, de modo a promover ações concretas que busquem uma melhor organização daquele espaço com vistas a alcançar uma revitalização urbanoambiental, e melhoria na qualidade de vida desta população.

\section{Referências}

AESA (Agência Executiva de Gestão das Águas do Estado da Paraíba). Gestão dos recursos hídricos na Paraíba. Disponível em: <http://www.aesa.pb.gov.br/gestao/>. Acesso em: 10 ago. 2015.

AGRA FILHO, S. S. Conflitos ambientais e os instrumentos da Política Nacional de Meio Ambiente. eGesta Revista Eletrônica de Gestão de Negócios - v. 4, n. 2, abr.-jun./2008, p. 127-140. ISSN 1809-0079. Disponível em: <http://www.unisantos.br/mestrado/gestao/egesta/artigos/149.pdf>. Acesso em: 25 ago. 2015.

ALVES, T. L. B.; LIMA, V. L. A.; FARIAS, A. A. de. Impactos ambientais no rio Paraíba na área do município de Caraúbas - PB: região contemplada pela integração com a bacia hidrográfica do Rio são Francisco. Revista Caminhos de Geografia Uberlândia, v. 13, n. 43 out/2012 p. 160-173. ISSN 1678-6343. Disponível em: <http://www.seer.ufu.br/index.php/caminhosdegeografia/>. Acesso em: 15 out. 2015.

ARAÚJO, J. C. de. Gestão das águas de pequenos açudes na região semiárida. In: MEDEIROS, Salomão de Sousa et al. (Eds). Recursos hídricos em regiões áridas e semiáridas. Campina Grande, PB: Instituto Nacional do Semiárido, 2011.

\section{POLÊM!CA $\mid$ LABORE}

Polêmica - Revista Eletrônica da Uerj - Rua São Francisco Xavier, 524, $1^{\circ}$ andar bloco D, sl.1001 • Tels.: +55 21 2334-4088 / 4087 • http://www.e-publicacoes.uerj.br/index.php/polemica/index http://www.labore.uerj.br • laboreuerj@yahoo.com.br 
BARBOSA, E. M. Introdução ao Direito Ambiental. Campina Grande: EDUFCG, 2007.

BRAGA, R. (Org.); CARVALHO, P. F. (Org.). Recursos Hídricos e Planejamento Urbano e Regional. 1. ed. Rio Claro: Laboratório de Planejamento Municipal, 2003. (Boletim Técnico, 131).

BRASIL. Código Florestal Brasileiro. Lei Federal nº 4.771/1965. Brasília.

Política Nacional de Meio Ambiente. Lei Federal nº 6.938/81. Brasília, 1981.

Política Nacional de Recursos Hídricos. Lei Federal n. 9.433/97. Brasília, 1997.

BORCARDIM, C. R. A Gestão de bacias hidrográficas urbanas: A experiência de Curitiba. 2008.

Dissertação (Programa de Pós-Graduação em Gestão Urbana). Pontifícia Universidade Católica do Paraná. Curitiba. Brasil.

BOTELLHO, R. G. M. \& SILVA, A. S. da. Bacia hidrográfica e qualidade Ambiental. In: VITTE, A. C.; GUERRA, A. J. T. (Orgs.). Reflexões sobre a Geografia Física no Brasil. Rio e Janeiro: Bertrand Brasil, 2004.

CHIZZOTTI, A. Pesquisa em Ciências Humanas e Sociais. 2a Edição. São Paulo: Cortez, 1995.

CONAMA - Conselho Nacional do Meio Ambiente. Resolução nº 001, de 23 de janeiro de 1986. Dispõe sobre critérios básicos e diretrizes gerais para o Relatório de Impacto Ambiental. Disponível em:

<http://www.mma.gov.br/port/conama/legiabre.cfm?codlegi=23>. Acesso em: 13 ago. 2015.

CONAMA - Conselho Nacional do Meio Ambiente. Resolução no 303, de 20 de março de 2002. Dispõe sobre parâmetros, definições e limites de Áreas de Preservação Permanente. Disponível em:

<http://www.mma.gov.br/port/conama/legiabre.cfm?codlegi=299>. Acesso em: 13 ago. 2015.

COSTA, D. S. B. dá; ARAÚJO, M. P. de. Turismo: vantagens ou perdas para as comunidades locais? Caos Revista Eletrônica de Ciências Sociais/UFPB, N 21 Novembro 2012. Dossiê Cultura \& Ambiente.

DORnElles, C. T. A. Percepção Ambiental: Uma análise da Bacia Hidrográfica do Rio Monjolinho, São Carlos, SP. 2006. Dissertação (Ciências da Engenharia Ambiental). Universidade de São Paulo. São Paulo.

GIL, A. C. Como elaborar projetos de pesquisa. 5. ed. São Paulo: Atlas, 2008.

IBGE. Instituto Brasileiro de Geografia e Estatística. Cidades. Paraíba, João Pessoa. 2010. Disponível em: <http://cidades.ibge.gov.br/xtras/perfil.php?codmun=250750>. Acesso em: 06 abr. 2015.

LIMA, M. A. S. Segregação sócio-espacial e desenho urbano em assentamentos espontâneos: o caso do bairro São José em João Pessoa PB. Revista Monolito Arquitetura como cultura. Vol. 072.06 Maio, 2006: ISSN1809-6298. Disponível em: <http://www.vitruvius.com.br/revistas/read/arquitextos/06.072/356>. Acesso em: 02 mai. 2015.

MEDEIROS, M.C.S. Percepção ambiental dos moradores ao entorno do açude de Bodocongó em Campina Grande - PB. Dissertação (Pós-graduação em Recursos Naturais). Universidade Federal de Campina Grande. Campina Grande - PB. 2013.

MENDONÇA, F. Aspectos da problemática ambiental urbana da cidade de Curitiba/PR e o mito da capital ecológica. GEOUSP Espaço e Tempo, São Paulo, n. 12, 2002.

NETO, A. T.; SANTOS, D.G.; BRITO, J. L. S. Os impactos ambientais urbanos no entorno do distrito industrial - 1, em Uberaba MG. Revista Caminhos de Geografia. v. 8, n. 24. p. 1 - 14. Dez/2007. Disponível em:

<http://www.seer.ufu.br/index.php/caminhosdegeografia/article/view/15544/8795>. Acesso em: 29 de out. 2015.

\section{POLÊM!CA $\mid$ LABORE}

Polêmica - Revista Eletrônica da Uerj - Rua São Francisco Xavier, 524, $1^{\circ}$ andar bloco D, sl.1001 • Tels.: +55 21 2334-4088 / 4087 • http://www.e-publicacoes.uerj.br/index.php/polemica/index http://www.labore.uerj.br • laboreuerj@yahoo.com.br 
PREFEITURA MUNICIPAL DE JOÃO PESSOA. Casas do projeto de urbanização da PMJP no bairro São José serão gratuitas. Paraíba, 2011. Disponível em: <http://www.joaopessoa.pb.gov.br/casas-do-projeto-deurbanizacao-da-pmjp-no-bairro-sao-jose-serao-gratuitas/>. Acesso em: 06 set. 2015.

SANTOS, M. Manual de Geografia Urbana. 2. ed. São Paulo: Hucitec, 1981.

SOBREIRA, L. C. Áreas susceptíveis a inundações na Bacia do Rio Jaguaribe - PB. João Pessoa-PB: 2006, $34 \mathrm{p}$.

SOUZA FILHO, F. de A. A Política Nacional de Recursos Hídricos: Desafios para sua implantação no semiárido brasileiro. In: MEDEIROS, Salomão de Sousa et al. (Eds). Recursos hídricos em regiões áridas e semiáridas. Campina Grande, PB: Instituto Nacional do Semiárido, 2011.

PEREIRA, S. S. Panorama da Gestão dos Resíduos Sólidos de Serviço de Saúde na Cidade de Campina Grande/PB: um enfoque da percepção ambiental apresentada por profissionais da saúde. 2009, $182 \mathrm{f}$. Dissertação (Mestrado em Desenvolvimento e Meio Ambiente). Universidade Federal e Estadual da Paraíba, Campina Grande, 2009.

PHILIPPI JR., A. Interdisciplinaridade em Ciências Ambientais. São Paulo: Signus Editora, 2000.

TUCCI, C. E. M. Gestão das águas no Brasil. Brasília: UNESCO, 2001.

ZHOURI, A.; LASCHEFSKI. K. Conflitos Ambientais. Texto inspirado na Introdução do livro Desenvolvimento e Conflitos Ambientais: Um Novo Campo de Investigação. In: ZHOURI, A.; LASCHEFSKI, K. (org.). Desenvolvimento e conflitos ambientais. Belo Horizonte: Editora UFMG, 2010, p. 11-34. Disponível em: <http://conflitosambientaismg.lcc.ufmg.br/wp-content/uploads/2014/04/ZHOURI_LASCHEFSKI__Conflitos_Ambientais.pdf $>$. Acesso em: 06 abr. 2016.

Recebido em: 21/12/2015.

Aceito em: 22/03/2016.

\section{POLÊM!CA $\mid$ LABORE}

Polêmica - Revista Eletrônica da Uerj - Rua São Francisco Xavier, 524, $1^{\circ}$ andar bloco D, sl.1001 • Tels.: +55 21 2334-4088 / 4087 • http://www.e-publicacoes.uerj.br/index.php/polemica/index http://www.labore.uerj.br • laboreuerj@yahoo.com.br 